\title{
Mapping inter-industrial CO2 flows within China
}

Bai, Hongtao; Feng, Xiangyu; Hou, Huimin; He, Gang; Dong, Yan; Xu, He

Published in:

Renewable and Sustainable Energy Reviews

Link to article, DOI:

10.1016/j.rser.2018.05.054

Publication date:

2018

Document Version

Peer reviewed version

Link back to DTU Orbit

Citation (APA):

Bai, H., Feng, X., Hou, H., He, G., Dong, Y., \& Xu, H. (2018). Mapping inter-industrial CO2 flows within China. Renewable and Sustainable Energy Reviews, 93, 400-408. https://doi.org/10.1016/j.rser.2018.05.054

\section{General rights}

Copyright and moral rights for the publications made accessible in the public portal are retained by the authors and/or other copyright owners and it is a condition of accessing publications that users recognise and abide by the legal requirements associated with these rights.

- Users may download and print one copy of any publication from the public portal for the purpose of private study or research.

- You may not further distribute the material or use it for any profit-making activity or commercial gain

- You may freely distribute the URL identifying the publication in the public portal

If you believe that this document breaches copyright please contact us providing details, and we will remove access to the work immediately and investigate your claim. 
$4 \quad{ }^{a}$ College of Environmental Science and Engineering, Nankai University, Tianjin 300350,

5 China

$6{ }^{\mathrm{b}} \mathrm{MOE}$ Key Laboratory of Pollution Processes and Environmental Criteria, Nankai

7 University, Tianjin 300350, China

8 'Department of Technology and Society, College of Engineering and Applied Sciences,

9 Stony Brook University, Stony Brook, New York 11794, United States of America

10 dQuantitative Sustainability Assessment, Department of Management Engineering,

11 Technical University of Denmark, Kgs. Lyngby, 2800, Denmark

To whom correspondence should be addressed:

14 Hongtao Bai: baiht@nankai.edu.cn

15 Gang He: Gang.He@stonybrook.edu 
1 Abstract: Like inter-regional $\mathrm{CO}_{2}$ leakages, good $\mathrm{CO}_{2}$ emission performances from downstream industries in the industrial chain often result in high direct levels of $\mathrm{CO}_{2}$ emissions in upstream sectors. Thus, it is necessary to rethink industrial carbon policies from the perspective of consumer responsibility. As the largest emitter of $\mathrm{CO}_{2}$ in the world, China has a very comprehensive industrial system. In this study, we traced fuelrelated $\mathrm{CO}_{2}$ flows between 30 Chinese industrial sectors in 2012 and explored the specificities of these flows on aggregate $\mathrm{CO}_{2}$ emission abatement for the entire economy. Previous studies have focused on carbon abatement policies instituted by industries generating high direct $\mathrm{CO}_{2}$ emissions, but our results demonstrate that paying more attention to $\mathrm{CO}_{2}$ importers better limits the consumption of energy-intensive materials. The construction sector, a major $\mathrm{CO}_{2}$ flow destination because of the largescale infrastructure required to support rapid urbanization in China, exhibits the greatest transfer of embodied $\mathrm{CO}_{2}$ from energy suppliers and from the producers of energyintensive materials. Our sensitivity analysis indicates that the construction sector shows considerable carbon abatement potential, which is surprisingly much greater than what is feasible for most high-carbon industries. Shifting more attention to industries that consume large amounts of embodied $\mathrm{CO}_{2}$ may help achieve more cost-effective decreases in $\mathrm{CO}_{2}$ emissions in absolute terms.

\section{Highlights:}

- The IO model and HEM are used to identify inter-industrial CO2 flows

- Fuel-related CO2 flows between all 30 industrial sectors in China are mapped

- Industrial carbon policies facilitating $\mathrm{CO} 2$ emission abatement are determined

- Construction sector shows considerable carbon abatement potential

Keywords: Carbon Emissions Embodied in Trade; Inter-Industrial Carbon Transfer; Hypothetical Extraction Method; Carbon Abatement Potential 


\section{1. Introduction}

$\mathrm{CO}_{2}$ emissions are closely associated with industrial activities [1]. Local climate policy makers worldwide have always paid more attention to industries that generate high levels of direct $\mathrm{CO}_{2}$ emissions (i.e., high-carbon industries, such as those of the energy sector; hereafter considered the same) to achieve regional low-carbon transformations. This largely reflects the production-based accounting principle, in which the producer is responsible for abating $\mathrm{CO}_{2}$ emissions [2]. Consequently, many compulsory measures are being undertaken in regions and industries that emit large volumes of $\mathrm{CO}_{2}$. International climate change negotiations have been based largely on this production-based principle [3]. Thus, China has instituted industrial restructuring by controlling the growth of high-carbon industries and by encouraging the development of low-carbon industries (i.e., industries generating low levels of direct $\mathrm{CO}_{2}$ emissions; hereafter considered the same) [4].

However, such production-based policies may not always effectively decrease total $\mathrm{CO}_{2}$ emissions throughout the entire economy. Developed countries/regions may decrease $\mathrm{CO}_{2}$ emissions within their territorial areas, while increasing their carbon footprints in other countries/regions [5, 6]. Shifting the focus to low-carbon industries within a region may decrease regional $\mathrm{CO}_{2}$ emission intensity levels but may not decrease total $\mathrm{CO}_{2}$ emissions [7]. The economic system represents an interdependent and integrated collection of various industries. Production behavior is believed to be provoked or even determined by consumer demand on the industrial supply chain [810]. Embodied $\mathrm{CO}_{2}$ emissions and consumption-based accounting principles have therefore been proposed as ways to increase the range of $\mathrm{CO}_{2}$ emission mitigation options [11-14]. $\mathrm{CO}_{2}$ emissions embodied in products and intermediate goods travel between regions and industries through upstream and downstream flows within the 
economy.

The inter-regional $\mathrm{CO}_{2}$ emission flows have been well identified over the past few years, focusing on both international $[9,15-20]$ and domestic trade $[6,21-26]$. These studies show that the global economy has been closely interlinked through its complex supply chain. Low $\mathrm{CO}_{2}$ emissions in downstream industries often cause high direct $\mathrm{CO}_{2}$ emissions in upstream sectors. Similar to inter-regional $\mathrm{CO}_{2}$ leakages, the transfer of inter-industrial $\mathrm{CO}_{2}$ flows embodied in products along the supply chain are also complicated. $\mathrm{CO}_{2}$ emissions associated with complex links between industrial sectors have not been well studied [27]. Although numerous studies emphasize the importance of production-based $\mathrm{CO}_{2}$ emissions and their driving forces [28-37], it is argued that industrial embodied $\mathrm{CO}_{2}$ emissions better represent $\mathrm{CO}_{2}$ burdens. Using a multiregional input-output (IO) model, industrial embodied $\mathrm{CO}_{2}$ emissions have been analyzed in many of the inter-regional studies mentioned above. To evaluate interindustrial $\mathrm{CO}_{2}$ emission transfers, an economic network model was used to trace $\mathrm{CO}_{2}$ emissions in global supply chains [27]; these models are typically limited in resolution to global to regional scales. In addition, the $\mathrm{CO}_{2}$ emissions embodied in the supply chain of several specific sectors, such as services, manufacturing, and construction industries, have also been discussed [38-40]. Several studies have demonstrated links between $\mathrm{CO}_{2}$ emissions across all different industrial sectors of a country, using a hypothetical extraction method (HEM) [7, 41-43]. However, they have largely focused on relationships between industrial clusters rather than $\mathrm{CO}_{2}$ flows between sectors. In developing countries like China, industrialization is a necessary pathway to economic prosperity. Accurate knowledge of inter-industrial $\mathrm{CO}_{2}$ flows can be a step toward global climate change mitigation. Consequently, it is necessary for local climate policy makers worldwide, especially those in developing countries, to rethink the appropriate 
industrial strategies for climate mitigation from a consumer responsibility perspective. As the world's second largest economy, reflecting a vast landmass, huge population, and rich natural resources, China has built a comprehensive industrial system. We focus on China, as a key example, and attempt to identify industries that require large embodied $\mathrm{CO}_{2}$ emissions to satisfy consumer demands (referred to as primary destinations of embodied $\mathrm{CO}_{2}$ flows). Our aim is to determine whether policies focusing on low-carbon industries more efficiently decrease $\mathrm{CO}_{2}$ emissions than productionbased measures. To answer this question, we need to obtain a full understanding of $\mathrm{CO}_{2}$ emission abatement effects achieved through various industrial policies. This requires quantification of embodied $\mathrm{CO}_{2}$ transferred between each pair of industrial sectors and determination of the sensitivities of different industrial sectors to total $\mathrm{CO}_{2}$ emissions of the national economy.

In this paper, we trace embodied $\mathrm{CO}_{2}$ flows between 30 industrial sectors and map detailed inter-industrial $\mathrm{CO}_{2}$ flows within China. To the best of our knowledge, it is the first quantitative map of embodied $\mathrm{CO}_{2}$ flow between pairs of industrial sectors in China. Furthermore, based on the proposed map, we re-examine industrial $\mathrm{CO}_{2}$ emission abatement potentials and determine which industrial carbon policies could best facilitate $\mathrm{CO}_{2}$ emission abatement in absolute terms for the entire Chinese economy. A sensitivity analysis is performed for each industrial sector to identify the most costeffective industrial carbon policy. Our results can be used to facilitate the development of Chinese industrial carbon policies and offer valuable guidelines for industrial strategies for climate mitigation worldwide, especially for developing countries.

\section{Materials and methods}


$5 \quad T_{i}=\frac{C_{i}}{x_{i}}$

\subsection{Industrial Fuel-Related $\mathrm{CO}_{2}$ Emissions}

The fossil fuel-related $\mathrm{CO}_{2}$ emissions generated by an industrial sector $i \quad\left(C_{i}\right)$ can be calculated as follows:

$$
\begin{aligned}
& C_{i}=\sum_{k=1}^{8} p_{i k} v_{k} \eta_{k} \\
& T_{i}=\frac{C_{i}}{x_{i}}
\end{aligned}
$$

$6 \quad$ where $T_{i}$ is the direct $\mathrm{CO}_{2}$ emission intensity of sector $i\left(\mathrm{t} / 10^{4} ¥\right) ; x_{i}$ is the total

7 output of sector $i\left(10^{4} ¥\right) ; C_{i}$ is the direct $\mathrm{CO}_{2}$ emissions generated by sector $i$

$8 \quad\left(\mathrm{t} / 10^{4} ¥\right) ; \eta_{k}$ is the $\mathrm{CO}_{2}$ emission factor for energy type $k(\mathrm{t} / \mathrm{TJ}) ; p_{i k}$ is the amount

9 of energy type $k$ consumed by sector $i(\mathrm{t})$; and $v_{k}$ is the conversion factor for energy type $k(\mathrm{TJ} /$ tce $)$. We considered the following eight fossil fuels: coal, coke, crude oil, diesel, fuel oil, gasoline, kerosene, and natural gas.

\subsection{Hypothetical Extraction Method}

The HEM has been used to explore the interdependent effects of changes in a sector or sectoral blocks [44-46]. This method assumes the target sector does not make inter-industrial transactions with other sectors in the hypothetical economic system. Data for the target sector are extracted to determine the influence of that sector on the entire economy, with a focus on the industrial linkages that define the target sector's relationship to the rest of the economy through direct and indirect intermediate purchases and sales made by the target sector.

In this method, an economy $Z$ with $n$ sectors can be described as follows:

$$
x=A x+f
$$


$1 \quad x=(I-A)^{-1} f=L f$

2 where $x=\left[\begin{array}{c}x_{1} \\ \mathrm{M} \\ x_{n}\end{array}\right]$ is the total output of $n$ sectors; $A=\left[\begin{array}{ll}a_{11} \mathrm{~L} & a_{1 n} \\ \mathrm{MO} & \mathrm{M} \\ a_{n 1} \mathrm{~L} & a_{n n}\end{array}\right]$ is the technical

3 coefficients matrix, in which $a_{i j}=z_{i j} / x_{j}$ is the amount of input from sector $i$

4 required directly to produce per unit output in sector $j$, and $z_{i j}$ represent the

5 intermediate output by sector $i$ to sector $j ; \quad L=(I-A)^{-1}=\left[l_{i j}\right]$ is known as the

6 Leontief inverse, in which $l_{i j}$ is the amount of output from sector $i$ required directly

7 and indirectly to produce per unit final demand from sector $j$; and $f=\left[\begin{array}{l}f_{1} \\ \mathbf{M} \\ f_{n}\end{array}\right]$ is the

8 total final demand.

9 Because this paper focuses on the inter-industrial transactions within the domestic

10 economy, we used the import similarity assumption to remove competitive imports. [47]

11 In this case, the economy $Z$ is divided into domestic transactions $D$ and imports

$12 M$. We assume that: if the fraction of a given input supplied by imports is the same for

13 each sector, then the same fraction $r_{i}$ of the total output in sector $i$ is attributed to

14 these imports, as follows:

15

$$
r_{i}=\frac{m_{i}}{\left(\sum_{j=1}^{n} z_{i j}\right)+f_{i}}=\frac{m_{i}}{x_{i}+m_{i}}
$$

16

$$
a_{i j}^{d}=\frac{z^{d}}{x_{j}}=\frac{\left(1-r_{i}\right) z_{i j}}{x_{j}}=\left(1-r_{i}\right) a_{i j}
$$

17

$$
A^{d}=\left[a^{d}{ }_{i j}\right]
$$


1 where $m_{i}$ is the import to sector $i, a^{d}{ }_{i j}$ is the amount of domestic input from sector

$2 \quad i$ required directly to produce per unit output from sector $j ; z^{d}{ }_{i j}$ is defined as the

3 domestic transactions by sector $i$ to sector $j$; and $A^{d}$ is the technical coefficients

4 matrix of the domestic intermediate input.

$5 \quad$ Next, if $S$ denotes the target sector and $-S$ is all remaining sectors, then $Z$

6 can be described as:

$7 \quad\left[\begin{array}{l}x_{s} \\ x_{-s}\end{array}\right]=\left[\begin{array}{ll}A_{s, s} & A_{s,-s} \\ A_{-s, s} & A_{-s,-s}\end{array}\right]\left[\begin{array}{l}x_{s} \\ x_{-s}\end{array}\right]+\left[\begin{array}{l}f_{s} \\ f_{-s}\end{array}\right]$.

8 If we define $\left[\begin{array}{ll}l_{s, s} & l_{s,-s} \\ l_{-s, s} & l_{-s,-s}\end{array}\right]$ as the Leontief inverse of this input-output model, then

$9 \quad\left[\begin{array}{l}x_{s} \\ x_{-s}\end{array}\right]=\left[\begin{array}{ll}l_{s, s} & l_{s,-s} \\ l_{-s, s} & l_{-s,-s}\end{array}\right]\left[\begin{array}{l}f_{s} \\ f_{-s}\end{array}\right]$.

10 Because the target sector $s$ is extracted and does not make inter-industrial 11 transactions with $-S$ in the hypothetical economic system, it is obvious that $12 A_{s,-s}=A_{-s, s}=0$ and the hypothetical economy $\bar{Z}$ is given by:

$$
\left[\begin{array}{l}
\bar{x}_{s} \\
\bar{x}_{-s}
\end{array}\right]=\left[\begin{array}{cc}
A_{s, s} & 0 \\
0 & A_{-s,-s}
\end{array}\right]\left[\begin{array}{l}
x_{s} \\
x_{-s}
\end{array}\right]+\left[\begin{array}{l}
f_{s} \\
f_{-s}
\end{array}\right]
$$

$14 \quad\left[\begin{array}{l}\bar{x}_{s} \\ \bar{x}_{-s}\end{array}\right]=\left[\begin{array}{cc}\left(I-A_{s, s}\right)^{-1} & 0 \\ 0 & \left(I-A_{-s,-s}\right)^{-1}\end{array}\right]\left[\begin{array}{l}f_{s} \\ f_{-s}\end{array}\right]$. the entire economy, is estimated by:

17

$$
\left[\begin{array}{c}
x_{s}-\bar{x}_{s} \\
x_{-s}-\bar{x}_{-s}
\end{array}\right]=\left[\begin{array}{cc}
l_{s, s}-\left(I-A_{s, s}\right)^{-1} & l_{s,-s} \\
l_{-s, s} & l_{-s,-s}-\left(I-A_{-s,-s}\right)^{-1}
\end{array}\right]\left[\begin{array}{l}
f_{s} \\
f_{-s}
\end{array}\right]
$$


1 Carbon emissions associated with the target sector $s$ can therefore be

2 deconstructed into four parts [46]: internal emissions (IE), which are $\mathrm{CO}_{2}$ emissions

3 associated with production processes in sector $s$; mixed emissions (ME), which are

$4 \mathrm{CO}_{2}$ emissions associated with the participation of sector $S$ and $-s$, reflecting $\mathrm{CO}_{2}$

5 emissions embodied in goods that are originally sold to $-s$ by $s$ after being

6 processed by $-S$ and are consequently repurchased by $S$ for production purposes; net

7 backward linkage emissions (NBLE), which are the net emissions imported by $S$ from

$8-s$ to meet the demands of $s$; and net forward linkage emissions (NFLE), which are

9 the net emission exports from $s\left(\mathrm{CO}_{2}\right.$ emitted by $s$ and used by $-s$ to produce

$10 f_{-s}$ ). Taking competitive imports into account, IE, ME, NBLE and NFLE can be

11 calculated, as follows:

12
IE: $T_{s}\left(I-A^{d}{ }_{s, s}\right)^{-1} f_{s}$

$\mathrm{ME}: T_{s}\left[l_{s, s}^{d}-\left(I-A_{s, s}^{d}\right)^{-1}\right] f_{s}$

NBLE: $T_{-s} l_{-s, s}^{d} f_{s}$

NFLE: $T_{s} l_{s,-s}^{d} f_{-s}$.

\subsection{Data Sources}

China is heavily reliant on fossil fuels [48]; however, only $\mathrm{CO}_{2}$ emissions generated through the industrial consumption of fossil fuels are considered here. Focusing on industrial $\mathrm{CO}_{2}$ emissions, the Chinese economy is disaggregated into 30 industrial sectors, accounting for more than $96.9 \%$ of the national energy consumption in 2012. Economic and energy-related data are taken from the Input-Output Table of China 2012 and from the Energy Statistical Yearbook 2013 [49-50]. $\mathrm{CO}_{2}$ emission 
1 factors are taken from the 2006 Intergovernmental Panel on Climate Change (IPCC)

2 Guidelines for National Greenhouse Gas Inventories [2]. Measures for converting

3 physical units into coal equivalents are from the Energy Statistical Yearbook 2013.

4 3. Results and Discussion

\subsection{Industrial $\mathrm{CO}_{2}$ Emissions}

Net Forward Linkage Emissions. NFLE reflect the inter-industrial embodied $\mathrm{CO}_{2}$ exports from an industry, i.e., $\mathrm{CO}_{2}$ emitted by an industry to meet the downstream demand; these are referred to as $\mathrm{CO}_{2}$ exports in this paper. As shown in previous studies, the Production and Supply of Electric Power and Heat Power sector (abbreviated names of all sectors are given in Table A.1) generates the largest amount of NFLE (3.47 $\mathrm{Bt} \mathrm{CO}_{2}$ ), accounting for $\sim 36.2 \%$ of all emissions generated in China (Fig. 1). The Production and Supply of Electric Power and Heat Power sector is the primary energy supplier and burns large amounts of fossil fuels to satisfy the energy demands of other industries [51], thus dominating the supply chain of China's modern economy. Industrial NFLE in China are centralized, with $\sim 76.2 \%$ of NFLE being produced by the following three sectors: The Production and Supply of Electric Power and Heat Power sector ( $\sim 36.2 \%$ of total NFLE); the Petroleum Processing and Coking sector ( $\sim 21.0 \%)$, and the Metals Mining and Dressing sector ( 19.0\%). Thus, the top seven industries of China generate more than $95 \%$ of its industrial $\mathrm{CO}_{2}$ exports.

Net Backward Linkage Emissions. NBLE reflect inter-industrial embodied $\mathrm{CO}_{2}$ imports; therefore, the NBLE of an industry reflect direct and intermediate purchases from upstream sectors, which are later referred to as $\mathrm{CO}_{2}$ imports in this paper. As is shown in Fig. 1, the Construction sector is a major generator of NBLE, 'absorbing' $2.86 \mathrm{Bt}$ of $\mathrm{CO}_{2}$ in 2012 ( $29.8 \%$ of all embodied $\mathrm{CO}_{2}$ emissions in 2012). The rapid 
urbanization of China has enhanced activity in the Construction sector, as shown in Fig. $A .4$, and the growing demand for energy-intensive materials (e.g., iron and steel) by this sector strongly affects inter-industrial $\mathrm{CO}_{2}$ flows throughout the Chinese economy. The second largest embodied $\mathrm{CO}_{2}$ emission absorber is the Service sector, responsible for $\sim 15.5 \%$ of all embodied $\mathrm{CO}_{2}$ emissions. This sector is also stimulated by the urbanization boom in China. However, the values for NBLE from other sectors are much lower, and no other sector accounts for more than $10 \%$ of the total NBLE in China.

Net Emission Transfers The difference between the NFLE and NBLE is defined as the net emission transfer value. We found that 13 industrial sectors are net $\mathrm{CO}_{2}$ exporters, while the other 17 industrial sectors are net $\mathrm{CO}_{2}$ importers. Interestingly, importers with large NBLE and exporters with large NFLE are very different (Fig. A.1). Excluding the Transport, Storage, and Post sector and the Chemical Products sector, which are the only balanced sectors, few industries exhibit high levels of both $\mathrm{CO}_{2}$ imports and $\mathrm{CO}_{2}$ exports. As is shown in Fig. A.1, sectors having larger NBLE often exhibit better $\mathrm{CO}_{2}$ emission performances, while sectors having higher NFLE exhibit much higher levels of carbon intensity.

\subsection{Industrial $\mathrm{CO}_{2}$ Emissions Flows}

In this section, we trace $\mathrm{CO}_{2}$ imports and exports (i.e., embodied $\mathrm{CO}_{2}$ flows) between all 30 industrial sectors of China. Our data are shown as a chord diagram (Fig. 2). To better visualize key linkages, industries with few $\mathrm{CO}_{2}$ transfer flows are removed, leaving 15 significant nodes in Fig. A.2. A complete flow dataset is given in Table A.5. As Fig. 2 shows, the Production and Supply of Electric Power and Heat Power sector, the Petroleum Processing and Coking sector, and the Metals Mining and Dressing sector are the most significant sources of industrial $\mathrm{CO}_{2}$ flows in China. These 
1 are all widely recognized as high-carbon industries and as key direct emitters of $\mathrm{CO}_{2}$.

2 These sectors generate energy and manufacture energy-intensive materials, and high

3 NFLE associated with these sectors are caused by and are mainly transferred to their

4 consumers (i.e., the Construction sector, the Service sector, and the Transportation

5 Equipment sector) (Fig. A.3a). Previous studies have focused on the roles of these

6 sectors in mitigating $\mathrm{CO}_{2}$ emissions, as they are the largest net $\mathrm{CO}_{2}$ exporters, have

7 powerful inter-industry effects, and less mixed effects can be achieved in these

8 industries than in others [41]. It has been argued that promoting energy efficiency and

9 shifting to cleaner energy-use are the most important ways of decreasing total $\mathrm{CO}_{2}$

10 emissions in these sectors [30-37, 52].

$\mathrm{Up}$ to 17 industries are found to represent the main destinations of industrial $\mathrm{CO}_{2}$

flows, and they account for $\sim 97.4 \%$ of total imports. The Construction sector is the most important receiver of embodied $\mathrm{CO}_{2}$, and so it is reasonably identified as being the main $\mathrm{CO}_{2}$ flow destination. The Production and Supply of Electric Power and Heat Power sector, the Metals Mining and Dressing sector, and the Petroleum Processing and Coking sector are the main embodied $\mathrm{CO}_{2}$ providers to the Construction sector, as shown in Fig. A.3b. The Construction sector required $\sim 2.86 \mathrm{Bt}$ of $\mathrm{CO}_{2}$ in 2012 from electricity and heat suppliers, as well as building material manufacturers, although it generated low levels of direct emissions. Of the total embodied $\mathrm{CO}_{2}$ levels required for the Construction sector, $\sim 34.4 \%$ is generated from The Production and Supply of Electric Power and Heat Power sector and $23.6 \%$ is generated from the Metals Mining and Dressing sector. The Chinese construction sector therefore strongly stimulates the expansion of energy-intensive material producers, which are emitting increasing levels of $\mathrm{CO}_{2}$. It has been suggested that the amount of embodied $\mathrm{CO}_{2}$ consumed by the Construction sector increased following a quadratic curve between 1994 and 2012, and 
that the use of energy-intensive materials has contributed to more than $80 \%$ of this increase [33].

Meanwhile, the Service sector is the second important destination for Chinese industrial embodied $\mathrm{CO}_{2}$ flows. This sector consumes a large amount of electricity and gasoline. Of the total embodied $\mathrm{CO}_{2}$ levels (1.49 $\mathrm{Bt}$ of $\left.\mathrm{CO}_{2}\right)$ required for the Service sector in 2012, 37.3\% is generated from The Production and Supply of Electric Power and Heat Power sector and $\sim 26.6 \%$ is generated from the Petroleum Processing and Coking sector. The Transportation Equipment sector, the Electrical Machinery and Apparatus sector, and the Communication, Computers and Other Electronic Equipment sector are also significant embodied $\mathrm{CO}_{2}$ destinations, consuming $\sim 0.74, \sim 0.57$, and $\sim 0.51 \mathrm{Bt}$ of $\mathrm{CO}_{2}$ in 2012 , respectively. High levels of embodied $\mathrm{CO}_{2}$ consumption in these equipment-manufacturing industries demonstrate the dominant role of Chinese products in the global economy.

The $\mathrm{CO}_{2}$ flow map shows that the Construction sector is the main source of Chinese $\mathrm{CO}_{2}$ emissions. Unfortunately, the Construction sector generates such low levels of direct emissions that appropriate attention has not been paid to its potential role in decreasing $\mathrm{CO}_{2}$ emissions. For example, China's National Plan on Climate Change (2014-2020) has imposed priorities to restrict high carbon industries other than the Construction sector. Under a new paradigm, focusing on sectors generating high NBLE could increase the number of $\mathrm{CO}_{2}$ abatement options available to decision makers. For example, reasonable measures focused on controlling the large-scale expansion of infrastructure, construction activity workloads, and improving materialuse efficiency in the Construction sector may generate better mitigation potentials than current measures. It is therefore worth identifying the specific effects that $\mathrm{CO}_{2}$ importers have on aggregate $\mathrm{CO}_{2}$ emissions of the entire Chinese economy by assessing 
their accumulative effects through the demand chain, as outlined below.

\subsection{Analysis of Carbon Abatement Potentials}

Previous studies have focused on origins (i.e., industries generating high NFLE, such as the Production and Supply of Electric Power and Heat Power sector, the Metals Mining and Dressing sector, and the Coal Mining and Dressing sector) as primary drivers of Chinese $\mathrm{CO}_{2}$ emissions. However, we argue that $\mathrm{CO}_{2}$ emission abatement may be more effectively achieved by regulating demands from downstream industries. We conducted a sensitivity analysis based on a one-industry-at-a-time approach to identify how industrial $\mathrm{CO}_{2}$ emission abatement levels could be more effectively achieved in China than by applying regular climate policies. We took industrial scale adjustments, energy efficiency improvements, and material efficiency into account. Assuming that all inter-relationships between the 30 industrial sectors represented by the Leontief inverse matrix coefficients are fixed, we estimated the volume of national total $\mathrm{CO}_{2}$ emissions that could be decreased ( $\triangle T C E$ ) through a $1 \%$ change in industrial scale (downsizing), or a 1\% improvement in the efficiency of energy-use or material-use by the target industry.

\section{(1) Industrial Scale Adjustments}

A change in total $\mathrm{CO}_{2}$ emissions in China caused by an industrial-scale adjustment $\left(\triangle T C E_{\text {scale }}\right.$ ) involves decreased direct emissions (Scope I) and decreased indirect emissions (Scopes II \& III), as described in the pragmatic ICLEI-Local Governments for Sustainability approach [54]. Downscaling any industry will decrease the level of fossil fuel consumption of that industry. The related decrease in $\mathrm{CO}_{2}$ emissions is defined as $\Delta C E_{\text {direct }}$ and is calculated from internal emissions, mixed emissions, and NFLE associated with industry $i[7]$. This variable reflects the visible change within 
1 the target industry and has typically been the focus of previous policy-making processes.

2 In addition to fuel combustion, secondary energy (e.g., electricity and heat)

3 consumption and non-energy material-use will decline, causing all providers of

4 embodied $\mathrm{CO}_{2}$ (intermediate good suppliers) to decrease their direct emissions (i.e.,

$\left.5 \Delta N B L E_{i}\right)$. In this case, $\triangle C E_{\text {indirect }}$ reflects the industrial driving effect of the target

6 sector's scale adjustments on the rest of the economy, especially on upstream industries.

7 The equation used to calculate $\triangle T C E_{\text {scale }}$ is shown below.

8

9

$$
\Delta T C E_{\text {scale }}=\Delta C E_{\text {direct }}+\Delta C E_{\text {indirect }}=\left(\Delta I E_{i}+\Delta M E_{i}+\Delta N F L E_{i}\right)+\Delta N B L E_{i}
$$

where $\triangle N B L E_{i}$ is the change in embodied $\mathrm{CO}_{2}$ imports for industry $i$ from other industrial sectors.

The abatement potential of a $1 \%$ decrease in industrial activity in each sector is shown in Fig. 3a. Direct $\mathrm{CO}_{2}$ emissions from the Production and Supply of Electric Power and Heat Power sector, the Petroleum Processing and Coking sector, and the Metals Mining and Dressing sector are decreased by large amounts, while the Construction sector and the Service sector eliminate large volumes of indirect emissions. The total abatement potential achieved by downscaling the Construction sector by $1 \%$ is almost the same as that achieved by downscaling the Production and Supply of Electric Power and Heat Power sector (currently recognized as the sector having the greatest potential for $\mathrm{CO}_{2}$ emission abatement) and is much greater than that achieved by downscaling other high-carbon industries, such as the Petroleum Processing and Coking sector and the Metals Mining and Dressing sector. The difference between these effects lies in the fact that downscaling the Production and Supply of Electric Power and Heat Power sector will decrease $\mathrm{CO}_{2}$ emissions directly generated by the Production and Supply of Electric Power and Heat Power sector, 
1 while downscaling the Construction sector will decrease emissions generated by many other sectors. The Chemical Products sector and the Transport, Storage, and Post sector are special cases, as downscaling them will clearly reduce both direct and indirect emissions. The total abatement potentials offered by the Chemical Products sector and the Transport, Storage, and Post sector are important because they generate large $\mathrm{CO}_{2}$ export values.

Cost-benefit analyses of $\mathrm{CO}_{2}$ emission decreases across all 30 sectors were also carried out, and their corresponding results are shown in Table A.10. The costs of downsizing are roughly estimated by changing the target industrial export values. Unlike previous industrial $\mathrm{CO}_{2}$ abatement cost-benefit analyses, we integrated decreases in embodied $\mathrm{CO}_{2}$ emissions into this calculation. The energy sectors, such as the Production and Supply of Electric Power and Heat Power sector and the Petroleum Processing and Coking sector, remain the most cost-efficient sectors to focus on, with $\mathrm{CO}_{2}$ emission abatement costs of $<2000 ¥$ per ton of $\mathrm{CO}_{2}$. However, it is concerning that several so-called low carbon industries, such as the Construction sector, have more cost-efficient carbon abatement effects than high-carbon sectors, such as the Metals Mining and Dressing sector and the Gas Production and Supply sector.

\section{(2) Energy Efficiency Improvements}

Energy efficiency is generally measured as an average value regardless of the sectoral energy mix. This makes it difficult to identify actual carbon abatement effects related to energy efficiency improvements. We classify industrial energy consumption into fossil fuel combustion (which generates direct $\mathrm{CO}_{2}$ emissions to the atmosphere) and secondary energy consumption (which generates indirect $\mathrm{CO}_{2}$ emissions imported from energy product suppliers). To simplify the model, five sectors (the Petroleum Processing and Coking sector, the Production and Supply of Electric Power and Heat 
1 Power sector, the Gas Production and Supply sector, the Petroleum and Natural Gas

2 Extraction sector, and the Coal Mining and Dressing sector) are defined as energy

3 product suppliers (related uncertainties are discussed in section 3.4). In this case, the

4 scale of the target industry is kept constant while the energy efficiency level is assumed

5 to increase by $1 \%$. The carbon abatement effect associated with greater energy

6 efficiency ( $\triangle T C E_{\text {energy }}$ ) can be estimated using the following equation:

7

$$
\Delta T C E_{\text {energy }}=\Delta C E_{\text {direct }}+\Delta C E_{\text {indirect }}=\left(\Delta I E_{i}+\Delta M E_{i}+\Delta N F L E_{i}\right)+\sum_{n=1}^{5} \Delta N B L E_{n, i},
$$

where $\triangle N B L E_{n, i}$ is the change in embodied $\mathrm{CO}_{2}$ imports for industry $i$ from energy product supplier $n$.

The $\mathrm{CO}_{2}$ emission abatement potential related to a $1 \%$ improvement in energy efficiency for each industry was estimated. As is shown in Fig. 3b, improving energy efficiency levels contributes considerably to $\mathrm{CO}_{2}$ emission reductions in every sector. Almost $38.5 \mathrm{Mt}$ of $\mathrm{CO}_{2}$ emissions can be prevented by improving energy efficiency levels by $1 \%$ in the Production and Supply of Electric Power and Heat Power sector, followed by the Petroleum Processing and Coking sector and the Metals Mining and Dressing sector, with respective reductions of about $22.8 \mathrm{Mt}$ and $20.3 \mathrm{Mt}$ in $\mathrm{CO}_{2}$ emissions. The majority of the total direct emission reduction can be attributed to these sectors. Excitingly, 17.2 $\mathrm{Mt}$ of $\mathrm{CO}_{2}$ emissions can be eliminated by improving the energy efficiency of the Construction sector. Unlike values for the Production and Supply of Electric Power and Heat Power sector, $98.0 \%$ of $\mathrm{CO}_{2}$ emissions eliminated from the Construction sector result from indirect emission reduction (Fig. 4), related to reducing the large volumes of electricity and heat consumed during construction. Although improving the energy efficiency of the Construction sector would have a limited effect on direct emissions, it could considerably help reduce national $\mathrm{CO}_{2}$ 
emissions.

It is worth mentioning that energy efficiency-related $\mathrm{CO}_{2}$ emission abatements in the Chemical Products sector and the Transport, Storage, and Post sector have hybrid effects (Fig. 4). Reduction of indirect emissions in these two sectors could contribute as much as $30 \%$ to the overall decrease in national $\mathrm{CO}_{2}$ emissions, although actual reductions will mainly occur in the Production and Supply of Electric Power and Heat Power sector, the Petroleum Processing and Coking sector, and the Coal Mining and Dressing sector. Our results suggest that we should not solely focus on direct $\mathrm{CO}_{2}$ emissions, but consider measures aimed at decreasing indirect $\mathrm{CO}_{2}$ emissions of high energy-use sectors.

\section{(3) Material Efficiency}

Decreasing the use of energy-intensive materials by promoting efficient material usage should abate direct $\mathrm{CO}_{2}$ emissions in upstream industries. The $\mathrm{CO}_{2}$ emission abatement potential of the entire economy achieved by promoting efficient use of nonenergy intensive materials in industry $i\left(\triangle T C E_{\text {matertial }}\right)$ can be estimated by determining changes in volumes of embodied $\mathrm{CO}_{2}$ imported by industry $i$ from all industries supplying non-energy products, using the following equation:

$$
\Delta T C E_{\text {matertial }}=\sum_{m=1}^{25} \Delta N B L E_{m, i} .
$$

where $\triangle N B L E_{m, i}$ is the change in embodied $\mathrm{CO}_{2}$ imports for industry $i$ from nonenergy product supply industry $m$. The non-energy product supply industries encompass all 25 sectors, excluding the Petroleum Processing and Coking sector, the Production and Supply of Electric Power and Heat Power sector, the Gas Production and Supply sector, the Petroleum and Natural Gas Extraction sector, and the Coal Mining and Dressing sector. 
As is shown in Fig. 3c, considerable volumes of $\mathrm{CO}_{2}$ emissions can be indirectly evaded by improving the efficiency of non-energy material-use in downstream industries. For instance, an $\sim 11.8 \mathrm{Mt} \mathrm{CO}_{2}$ emission reduction can be achieved through a $1 \%$ material efficiency increase in the Construction sector. This reduction stems from the manufacturers of building materials, e.g., the Metals Mining and Dressing sector which provides iron and steel and accounts for $\sim 57.3 \%$ of reductions, the Non-metallic Mineral Products sector supplying cement and glass which contributes $\sim 12.8 \%$ to reductions, and the Chemical Products sector providing architectural coatings and plastics, which contributes $\sim 13.3 \%$ (Fig. 5).

Overall, improving material efficiency accounts for more than $20 \%$ of the total abatement effects for many industries having high NBLE, such as the Construction sector and the Electrical Machinery and Apparatus sector (Table A.9). Fig. 3d shows that the total carbon abatement effect associated with industrial scale adjustment, as well as improved energy efficiency and material-use efficiency in the Construction sector $(\sim 58.0 \mathrm{Mt})$ is surprisingly much greater than for the Petroleum Processing and Coking sector ( 45.7 Mt) and the Metals Mining and Dressing sector ( 40.8 Mt), and only slightly less beneficial than those of the Production and Supply of Electric Power and Heat Power sector $(\sim 77.1 \mathrm{Mt})$. We conclude that improving energy and materialuse efficiency in downstream industries to reduce consumption of energy-intensive materials constitutes an efficient way of mitigating $\mathrm{CO}_{2}$ emissions in China.

\subsection{Uncertainty Analysis}

The economic system comprises a complicated, interdependent, and integrated set of industries. To investigate such interdependence, we made some assumptions and simplifications to build our models. Because models are simplified representations of 
real-world systems, they typically do not mimic actual conditions. The major sources of uncertainties in our method are outlined below.

Uncertainties Associated with Activity Data. (a) Default data regarding $\mathrm{CO}_{2}$ emission factors from the IPCC are used directly in this paper. Using the default data without any correction leads to inherited uncertainties. (b) Uncertainties and errors associated with the fossil fuel energy consumption data may stem from officially published statistical yearbooks in China [55]. (c) Differences in industrial classifications between the Input-Output Table of China 2012 and the Energy Statistical Yearbook 2013 of China resulted in the energy consumption data for several household sectors not being discussed separately. Because this study focuses on industrial $\mathrm{CO}_{2}$ emissions, we excluded the residential consumption sector and combined other sectors into the Service sector to yield 30 industrial sectors describing the Chinese economy. The residential consumption sector accounted for less than $3.2 \%$ of the total fossil fuel consumption in 2012 in China, as is shown in Table A.11. The 30 industrial sectors discussed in this paper provide a good overview of inter-industrial $\mathrm{CO}_{2}$ flows in China. Furthermore, we can easily compare our results with other relevant studies. For instance, we estimated that the Construction sector absorbed $\sim 2.86 \mathrm{Bt}$ of $\mathrm{CO}_{2}$ and was responsible for $29.8 \%$ of all Chinese embodied $\mathrm{CO}_{2}$ emissions in 2012; this is roughly consistent with estimates from previous studies [56-58].

Uncertainties Related to Modeling. The methods used herein were developed based on several assumptions. (a) The HEM assumes that all inter-relationships between sectors (i.e., the Leontief inverse matrix coefficients) are fixed, while one specific industry is extracted to determine the influence of that industry on the entire economy. The nature of this method could lead to uncertainties in our results. (b) In section 3.1 dealing with carbon abatement, we assume that all the products of the 
1 Petroleum Processing and Coking sector, the Production and Supply of Electric Power and Heat Power sector, the Gas Production and Supply sector, the Petroleum and Natural Gas Extraction sector, and the Coal Mining and Dressing sector are secondary energy types. Thus, these five sectors are defined as energy product suppliers. The other 25 sectors are assumed to only provide non-energy products. This simplification facilitated analysis of $\mathrm{CO}_{2}$ abatement potentials; however, some uncertainty is introduced and would need to be evaluated in further studies.

\section{Conclusions}

The high direct $\mathrm{CO}_{2}$ emission levels generated through manufacturing of energyintensive materials have previously been examined to abate $\mathrm{CO}_{2}$ levels. However, our results indicated that paying more attention to technological improvements in $\mathrm{CO}_{2}$ importing sectors could more effectively decrease the consumption levels of energyintensive materials. Like inter-regional $\mathrm{CO}_{2}$ leakages, industrial disparities create complex inter-industrial embodied $\mathrm{CO}_{2}$ flows. Strong $\mathrm{CO}_{2}$ emission performances in downstream industries often occurs at the expense of unavoidably high $\mathrm{CO}_{2}$ emissions in upstream sectors to meet the demands of the downstream industries. We traced embodied $\mathrm{CO}_{2}$ flows between 30 industrial sectors in 2012 in China and re-explored industrial $\mathrm{CO}_{2}$ emission abatement potentials from a consumer responsibility perspective. Uncertainties associated with the activity data and applied methods were also discussed.

Our results showed that the most important $\mathrm{CO}_{2}$ exporters are central to the Chinese industrial system. Two energy supplying sectors (the Production and Supply of Electric Power and Heat Power sector and the Petroleum Processing and Coking sector) and one metallurgical industry sector (the Metals Mining and Dressing sector) were the three most significant sources of industrial $\mathrm{CO}_{2}$ flows in China, contributing 
1 approximately $80 \%$ of the total $\mathrm{CO}_{2}$ exports. However, the Construction sector, the

2 main destination for $\mathrm{CO}_{2}$ emission flows, was the most significant destination for

3 embodied $\mathrm{CO}_{2}$. These $\mathrm{CO}_{2}$ emissions were transferred not only from energy suppliers

4 but also from energy-intensive material producers, with $\sim 34.4 \%$ derived from the

$5 \quad$ Production and Supply of Electric Power and Heat Power sector and $23.4 \%$ derived

6 from the Metals Mining and Dressing sector. This demonstrated that the large-scale

7 expansion of infrastructure resulting from rapid urbanization can explain the

8 tremendous increase in $\mathrm{CO}_{2}$ emissions that has occurred in China. Sensitivity analyses

9 indicated that the Construction sector could make significant $\mathrm{CO}_{2}$ emission abatement

10 contributions through scale adjustments, and improvements in energy and material

11 efficiency. The $\mathrm{CO}_{2}$ emission abatement potential of the Construction sector was

12 determined to be almost the same as that of the Production and Supply of Electric Power

13 and Heat Power sector, which is currently recognized as being the main sector in which

$14 \mathrm{CO}_{2}$ emission abatement should occur. The Construction sector's potential was shown

15 to be surprisingly much greater than that of other high-carbon industrial sectors. Non-

16 energy material efficiency improvements accounted for $\sim 20.3 \%$ of the Construction

17 sector $\mathrm{CO}_{2}$ emission abatement potential, originating mainly from building material

18 manufacturers (e.g., the Metals Mining and Dressing sector, and the Non-metallic

19 Mineral Products sector). The same phenomenon was found for other industries

20 presenting high $\mathrm{CO}_{2}$ import levels. In addition to promoting energy saving in energy-

21 intensive material manufacturing processes, future emission mitigation measures

22 should focus on decreasing consumption of energy-intensive goods in downstream

23 industries. For instance, to downscale construction activities, China should reform

24 urban planning and design, avoid construction of repetitive infrastructure, and create

25 stronger incentives for more efficient, inclusive, and sustainable urbanization processes. 
1 Lean construction methods should be adopted, while solid waste should be minimized

2 and recycled to more efficiently use energy-intensive material.

Many official carbon policies in China are aimed at meeting the $\mathrm{CO}_{2}$ peak target

4 by setting requirements for decreasing $\mathrm{CO}_{2}$ emissions on high-carbon industries $[4,59]$.

5 However, net $\mathrm{CO}_{2}$ exporters in the industrial chain will struggle to meet their targets in

6 absolute terms, if no measures are taken by importers of embodied $\mathrm{CO}_{2}$ to optimize

7 consumption through scale adjustment or technological improvements. Several

8 industries with low carbon intensity, such as the Construction sector and the Special

9 Purpose Machinery sector, have been found to have more cost-efficient carbon

10 abatement effects than those achievable by high-carbon sectors, such as the Metals

11 Mining and Dressing sector and the Gas Production and Supply sector. It has been

12 suggested that embodied $\mathrm{CO}_{2}$ emissions should be integrated into the industrial carbon

13 emission trading scheme, especially into industrial carbon credit allocations. Our results

14 showed that paying attention to the industries consuming the most embodied $\mathrm{CO}_{2}$ and

15 promoting efficient material-use may help us achieve more cost-effective decreases in

$16 \mathrm{CO}_{2}$ emissions in absolute terms.

ASSOCIATED CONTENT

\section{Conflict of Interests}

The authors declare no competing financial interests.

\section{Acknowledgements}

This research is supported by the Humanity and Social Science Youth Foundation of the Ministry of Education of China (grant number 17YJCZH002), the National Natural Science Foundation of China (41301648), the State Scholarship Fund of China 
1 (201606205026).

2

\section{References}

4 [1] International Energy Agency. $\mathrm{CO}_{2}$ Emissions from Fuel Combustion (IEA, 5 2016), https://www.iea.org/publications/freepublications/publication/CO2Emissionsfrom FuelCombustion_Highlights_2016.pdf (accessed Jan 13, 2017)

[2] Intergovernmental Panel on Climate change (2006) 2006 IPCC Guidelines for National Greenhouse Gas Inventories (Intergovernmental Panel on Climate change, Hayama, Kanagawa, Japan).

[3] UNFCCC, 2008. Kyoto Protocol Reference Manual: On Accounting of Emissions and Assigned Amount. United Nations Framework Convention on Climate Change. Bonn, Germany

[4] National Development and Reform Commission. National Plan on Climate Change (2014-2020), http://www.sdpc.gov.cn/gzdt/201411/W020141104591413713551.pdf (accessed Jan 13, 2017)

[5] Kanemoto, K.; Moran, D.; Hertwich, E. Mapping the carbon footprint of nations. Environ Sci Technol. 2016, 50(19): 10512-10517

[6] Feng, K.; Davis, S.; Sun, L.; Li, X.; Guan, D.; Liu, Y.; Liu, Z.; Hubacek, K. Outsourcing $\mathrm{CO}_{2}$ Within China. Proc Natl Acad Sci USA. 2013, 9(28): 1165411659

[7] Wang, Y.; Wang, W.; Mao, G.; Cai, H.; Zuo, J.; Wang, L.; Zhao, P. Industrial $\mathrm{CO}_{2}$ emissions in China based on the hypothetical extraction method: Linkage analysis. Energ Policy. 2013, 62: 1238-1244 
1 [8] Peters, G. From production-based to consumption-based national emission inventories. Ecol Econ. 2008, 65(1): 13-23

[9] Davis, S.; Caldeira, K. Consumption-based accounting of $\mathrm{CO}_{2}$ emissions. Proc Natl Acad Sci USA. 2010, 107 (12): 5687-5692.

[10] Springmann, M., Integrating emissions transfers into policy-making. Nature Clim Change. 2014, 4 (3): 177-181

[11] Munksgaard, J.; Pedersen, K. $\mathrm{CO}_{2}$ accounts for open economies: producer or consumer responsibility? Energ Policy. 2001, 29 (4): 327-334.

[12]Peters, G.; Hertwich, E. $\mathrm{CO}_{2}$ embodied in international trade with implications for global climate policy. Environ Sci Technol. 2008, 42 (5): 1401-1407

[13] Mozner, Z. A consumption-based approach to carbon emission accounting sectoral differences and environmental benefits. J Clean Prod. 2013, 42: 83-95.

[14]Bai, H.; Zhang, Y.; Wang, H.; Huang, Y.; Xu, H. A Hybrid Method for Provincial Scale Energy-related Carbon Emission Allocation in China. Environ Sci Technol. 2014, 48(5): 2541-2550

[15]Peters, G.; Minx, J.; Weber, C.; Edenhofer, O.; Affiliations, A. Growth in Emission Transfers via International Trade from 1990 to 2008. Proc Natl Acad Sci USA. 2011, 108(21): 8903-8908.

[16]Davis, S.; Peters, G.; Caldeira, K. The supply chain of $\mathrm{CO}_{2}$ emissions. Proc Natl Acad Sci USA. 2011, 108: 18554-18559.

[17]Jakob, M.; Marschinski, R. Interpreting trade-related $\mathrm{CO}_{2}$ emission transfers. Nature Clim Change. 2012, 3: 19-23.

[18]Xu, M.; Li, R.; Crittenden, J.; Chen, Y. CO2 emissions embodied in China's exports from 2002 to 2008: A structural decomposition analysis. Energ Policy. 2011, 39: 7381-7388. 
1 [19] Guo, J.; Zhang, Z.; Meng, L. China's provincial CO2 emissions embodied in international and interprovincial trade. Energ Policy. 2012, 42: 486-497.

[20]Jiang, X.; Chen, Q.; Guan, D.; Zhu, K.; Yang, C. Revisiting the global net carbon dioxide emission transfers by international trade: The impact of trade heterogeneity of China. J Ind Ecol. 2016, 20(3): 506-514.

[21]Feng, K.; Hubacek, K.; Sun, L.; Liu, Z. Consumption-based $\mathrm{CO}_{2}$ Accounting of China's Megacities: The case of Beijing, Tianjin, Shanghai and Chongqing. Ecol Indic. 2014, 47: 26-31.

[22]Meng, B.; Xue, J.; Feng, K.; Guan, D.; Fu, X. China’s inter-regional spillover of carbon emissions and domestic supply chains. Energ Policy. 2013, 61: 13051321.

[23]Chen, S.; Chen, B. Tracking Inter-Regional Carbon Flows: A Hybrid Network Model. Environ Sci Technol. 2016, 50:4731-4741.

[24]Zhang, B.; Qiao, H.; Chen, Z.; Chen, B. Growth in embodied energy transfers via China's domestic trade: Evidence from multi-regional input-output analysis. Appl Energ. 2016, 184: 1093-1105.

[25]Mi, Z.; Zhang, Y.; Guan, D.; Shan, Y.; Liu, Z.; Cong, R.; Yuan, X.-C.; Wei, Y.M.; Consumption-based emission accounting for Chinese cities. Appl Energ. 2016, 184: 1073-108.

[26] Chen, S.; Chen, B. Urban energy consumption: Different insights from energy flow analysis, input-output analysis and ecological network analysis. Appl Energ. 2015, 138: 99-107.

[27]Kagawa, S.; Suh, S.; Hubacek, K.; Wiedmann, T.; Nansai, K.; Minx, J. CO 2 emission clusters within global supply chain networks: Implications for climate change mitigation. Global Environ Chang. 2015, 35: 486-496. 
1 [28]Ang, B.; Su, B. Carbon Emission Intensity in Electricity Production: A Global Analysis. Energ Policy. 2016, 94: 56-63.

[29]Liu, N.; Ma, Z.; Kang, J. Changes in Carbon Intensity in China's Industrial Sector: Decomposition and Attribution Analysis. Energ Policy. 2015, 87: 28-38

[30]Lin, B.; Wang, X. Carbon emissions from energy intensive industry in China: Evidence from the iron \& steel Industry. Renew Sust Energ Rev. 2015, 47: 746754.

[31]Peng, L.; Zeng, X.; Wang, Y.; Hong, G. Analysis of Energy Efficiency and Carbon Dioxide Reduction in the Chinese Pulp and Paper Industry. Energ Policy. 2016, 80: 65-75.

[32] Xu, B.; Lin, B. Reducing $\mathrm{CO}_{2}$ Emissions in China's Manufacturing Industry: Evidence from Nonparametric Additive Regression Models. Energy. 2016, 101: $161-173$.

[33]Lu, Y.; Cui, P.; Li, D. Carbon Emissions and Policies in China's Building and Construction Industry: Evidence from 1994 to 2012. Build Environ. 2016, 95: 94103.

[34]Wang, X.; Lin, B. How to Reduce $\mathrm{CO}_{2}$ Emissions in China's Iron and Steel Industry. Renew Sust Energ Rev. 2016, 57: 1496-1505.

[35]Zhang, N.; Wei, X. Dynamic Total Factor Carbon Emissions Performance Changes in the Chinese Transportation Industry. Appl Energ. 2015, 146: 409-420. [36]Lin, B.; Zhang, Z. Carbon Emissions in China's Cement Industry: A Sector and Policy Analysis. Renew Sust Energ Rev. 2016, 58: 1387-1394.

[37]Lin, B.; Long, H. Emissions Reduction in China's Chemical Industry - Based on LMDI. Renew Sust Energ Rev. 2016, 53: 1348-1355.

[38]Zhang, W.; Peng, S.; Sun, C. $\mathrm{CO}_{2}$ emissions in the global supply chains of 
services_An analysis based on a multi-regional input-output model. Energ Policy. 2015, 86: 93-103.;

[39] Kucukvar, M.; Cansev, B.; Egilmez, G.; Onat, N.; Samadi, H. Energy-climate manufacturing nexus: New insights from the regional and global supply chains of manufacturing industries. Appl Energ. 2016, 184, 889-904.

[40]Hong, J.; Shen, G.; Guo, S.; Xue, F.; Zheng, W. Energy use embodied in China's construction industry: A multi-regional input-output analysis. Renew Sust Energ Rev. 2016, 53: 1303-1312.

[41]Zhao, Y.; Zhang, Z. Linkage Analysis of Sectoral $\mathrm{CO}_{2}$ Emissions Based on the Hypothetical Extraction Method in South Africa. J Clean Prod. 2015, 103: 916924.

[42]Qian, M.; Lu, Z. Based on assumptions extraction method of carbon industry department correlation analysis. China Population Resources and Environment. 2013, 9: 34-41

[43]Zhao, Y.; Liu, Y. Inter-regional Linkage Analysis of Industrial $\mathrm{CO}_{2}$ Emissions in China: An application of A Hypothetical Extraction Method. Ecol Indic. 2016, 61: 428-437.

[44]Cella, G. The Input-output Measurement of Inter Industry Linkages. Oxford B Econ Stat. 1984, 46(1): 73-84

[45] Guerra, A.; Sancho, F. Measuring Energy Linkages with the Hypothetical Extraction Method: An Application to Spain. Energy Econ. 2010, 32(4): 831-837. [46] Duarte, R.; Sánchez-Chóliz, J.; Bielsa, J. Water Use in the Spanish Economy: An Input-output Approach. Ecol Econ. 2002, 43(1): 71-85.

[47] Miller, R.; Blair, P. Input-Output Analysis: Foundations and Extensions, Cambridge, 2009 
1 [48]Liu, Z.; Guan, D.; Wei, W.; Davis, S.; Ciais, P.; Bai, J.; Peng, S.; Zhang, Q.

Reduced carbon emission estimates from fossil fuel combustion and cement production in China. Nature, 2015, 524: 335-338

[49] National Bureau of Statistics of China, China Statistical Yearbook 2012. China Statistics Press, 2013

[50] National Bureau of Statistics of China, China Energy Statistical Yearbook 2013. China Statistics Press, 2015

[51]He, G.; Avrin, A.; Nelson, J.; Johnston, J.; Mileva, A.; Tian, J.; Lammen, D. SWITCH-China: A Systems Approach to Decarbonizing China’s Power System. Environ Sci Technol. 2016, 50: 5467-5473

[52] Guo, Y.; Tian, J.; Chertow, M.; Chen, L. Greenhouse gas mitigation in Chinese eco-industrial parks by targeting energy infrastructure: a vintage stock model. Environ Sci Technol. 2016, 50: 11403-11413

[53] Krzywinski, M.; Schein, J.; Birol, I.; Connors, J.; Gascoyne, R.; Horsman,, D.; Jones, S.; Marra, M. Circos: an Information Aesthetic for Comparative Genomics. Genome Res. 2009, 19: 1639-1645

[54] Kennedy, C.; Steinberger, J.; Gasson, B.; Hansen, Y.; Hillman, T.; Havranek, M.; Pataki, D.; Phdungsilp, A.; Ramaswami, A.; Mendez, G. Methodology for inventorying greenhouse gas emissions from global cities. Energ Policy. 2010, 38 (9): $4828-4837$

[55]Geng, Y.; Tian, M.; Zhu, Q.; Zhang, J.; Peng, C. Quantification of provinciallevel carbon emissions from energy consumption in China. Renew Sust Energ Rev. 2011, 15 (8): 3658-3668.

[56] Guan. J.; Zhang, Z.; Chu, C. Quantification of building embodied energy in China using an input-out-based hybrid LCA model. Energy and Building. 2016, 110 : 
2 [57]Zhang, X.; Wang, F. Hybrid input-output analysis for life-cycle energy

3 consumption and carbon emissions of China's building sector, Building and

$4 \quad$ Environment. 2016, 104, 188-197

5 [58]Zhang, Z.; Wang, B. Research on the life-cycle $\mathrm{CO}_{2}$ emission of China's construction sector. Energy and Buildings. 2016, 112, 244-255

7 [59] National Development and Reform Commission. China's Policies and Actions 8 for Addressing Climate Change (2013),

$9 \quad$ http://qhs.ndrc.gov.cn/zcfg/201311/W020131107533601343247.pdf (accessed $10 \quad$ Jan 13, 2017) 